\title{
Peripheral neuropathy profile in various groups of diabetics
}

\author{
Pamela M Le Quesne, Clare J Fowler, Nicholas Parkhouse
}

\begin{abstract}
The results of applying a battery of peripheral nerve function tests in three groups of diabetics are reported. The tests examined the integrity of all the major subgroups of nerve fibres. The diabetics were grouped according to the clinical severity of their neuropathy: Group I-11 patients with long standing diabetes but clinically insignificant neuropathy, Group II-27 patients with mild neuropathy and Group III-23 patients with neuropathic foot lesions. As expected the incidence of abnormality of all functions increased from Group I to III, but within a group there was no clear pattern of differential involvement of different fibre types. The study has identified those tests that are suitable for detecting early neuropathy (warming and vibration perception thresholds and sensory nerve action potentials) and those which are likely to be useful in assessing deterioration or improvement (particularly vibration perception threshold), but since the different tests cannot be equally matched for sensitivity it is not possible to interpret the results in terms of the degree of pathological involvement of different fibre groups.
\end{abstract}

Although there has been clinical and pathological evidence that in some patients with diabetic neuropathy, small diameter nerve fibres may be more severely involved than larger ones, ${ }^{12}$ until recently quantification of the respective deficits has been difficult. However, since the advent of quantitative sensory testing ${ }^{3}$ there have been a number of studies of nerve function in diabetics at various stages of their disease which have incorporated assessment of small diameter nerve fibre function. ${ }^{412}$

We have developed a battery of tests which can be carried out within two hours, for measuring the various modalities of peripheral nerve function. These tests have been applied to three different groups of patients with diabetes mellitus to assess the extent of large and small fibre dysfunction at various stages of neuropathy. The study also provides evidence as to which of the tests gives the earliest indication of peripheral nerve damage and which tests, not necessarily the same, are most likely to be useful in detecting change in the severity of the damage. Information on these points is of increasing importance with the development of therapeutic measures designed to prevent the development of diabetic neuropathy or improve the established condition, and in epidemiological surveys of the incidence of neuropathy in diabetes. $^{13}$

\section{Methods}

ELECTROPHYSIOLOGY

1 Motor nerve fibres

The amplitude of the negative component of a compound muscle action potential recorded with surface electrodes over abductor hallucis was measured following supramaximal stimulation of the tibial nerve at the ankle.

\section{Large diameter sensory nerve fibres (Ab fibres)}

The peak-to-peak amplitude of the sural nerve action potential recorded at the ankle through bipolar surface electrodes $(4 \mathrm{~cm}$ apart $)$ was measured following supramaximal stimulation of the nerve $14 \mathrm{~cm}$ proximal in the calf and conduction velocity calculated.

\section{QUANTITATIVE SENSORY TESTS}

1 Ab sensory fibres

Vibration perception threshold was measured on the great toe with a biothesiometer (Ohio) using the ascending method of limits. The instruments used in this study were adjusted in the ICI laboratories to a standard calibration. The results obtained can therefore be equated with those obtained in various clinical trials in which biothesiometers standardised by ICI were used. Results obtained with instruments which have not been adjusted in this way may not be comparable. Despite this, and in view of the imprecision of the waveform, results were expressed in "biothesiometer units". The sensitivity and reproducibility of results obtained in this way have been described and discussed previously. ${ }^{14-16}$

\section{Thermal perception thresholds}

Threshold to cooling (Ad fibres) and to warming (C fibres) were measured on the instep with the Middlesex Thermal Tester as described by Fowler et al. ${ }^{17}$ Ramp stimuli at a constant rate of change were applied and threshold determined using "yes/no" responses and a modification of the up-down transformation rule.

3 Nociceptive C fibres

Axon reflex vasodilatation was measured on the 
instep with a laser Doppler flowmeter following stimulation by electrophoresis of acetylcholine as described by Parkhouse and Le Quesne. ${ }^{18}$ To ensure that any failure of reflex vasodilatation was not due to intrinsic vessel disease, the non-neurogenic capacity to vasodilate was measured following firm pressure with a dermograph (Lewis's red reaction). An index was calculated as the ratio of neurogenic to non-neurogenic dilatation. The response was considered abnormal if the absolute size of the flare and/or the index was reduced.

\section{AUTONOMIC FUNCTION TESTS}

\section{Vasomotor fibres}

Sympathetic reflex vasoconstriction was measured on the sole of the foot with a laser Doppler flowmeter following stimulation by an inspiratory gasp, held for $30 \mathrm{~s}$, and by immersion of the hand for $10 \mathrm{~s}$ in ice cold water at $4^{\circ} \mathrm{C} .{ }^{19}$

\section{Sudomotor fibres}

Sweating on the sole was measured by counting the number of active sweat glands appearing as dots when paper impregnated with bromphenol blue was pressed onto the instep following stimulation by electrophoresis of $10 \%$ pilocarpine for five minutes. Only innervated sweat glands respond to this stimulation, ${ }^{20}$ sweat glands being an exception to Cannon's law of denervation hypersensitivity.

\section{Cardiac autonomic function}

Because of time constraints in the length of the examination, only a single test was carried out. Six deep inspiratory and expiratory breaths were taken, each lasting $10 \mathrm{~s}$ and the maximumminimum beat difference was calculated ( $R R$ variability). The greatest difference was recorded.

\section{Subjects}

Three groups of diabetic subjects were studied. Patients with symptoms or signs of peripheral vascular disease or severe cardiac ischaemia were excluded. Sixty one patients were divided into the following clinical groups:

Group I-11 patients attending a diabetic clinic for more than 20 years who had not complained of symptoms attributable to peripheral neuropathy.

Group II-27 patients, who were taking part in a drug trial, who had clinical evidence of mild neuropathy on the basis of abnormal vibration perception assessed in the outpatient clinic but with no foot lesions.

Group III-23 patients with neuropathy and various foot complications of diabetes.

a) Five with skin lesions on the foot such as interdigital sepsis and paronychia.

b) 10 with typical neuropathic plantar ulcers.

c) Eight with Charcot arthropathy of the feet.

All the nerve function tests were carried out on Groups I and III. Nociceptive C and autonomic fibres in the foot were not examined in Group II.
Data obtained in our laboratories on control subjects were used in the assessment of abnormality.

\section{Statistical analysis}

Peripheral nerve function is known to deteriorate with age. In the control subjects, the results gave a better linear correlation with age after log transformation of the data. In addition when repeated observations were made on control subjects the data was heteroscedastic. For these reasons statistical analysis was carried out on log transformed data. The only exception was conduction velocity, to which these criteria did not apply, and a linear correlation with age was used. The vasodilatation index was a ratio of two measurements and therefore a linear correlation was also calculated.

The formula used for calculation of the $95 \%$ control limits of the regression on age was:

$a+b x$

$$
\pm 2 \mathrm{SD} \sqrt{1+1 / n+(x-\bar{x})^{2} / \Sigma\left(x_{i}-\bar{x}\right)^{2}}
$$

where $n=$ number of subjects, $a=$ intercept, $\mathrm{b}=$ slope, $\overline{\mathrm{x}}=$ mean age, $\mathrm{x}_{\mathrm{i}}=$ age of subject, $\mathrm{SD}=$ standard deviation of slope. Values in diabetics which fell outside these limits were considered abnormal.

\section{Results \\ Control data}

Data for control subjects obtained using the tests described are summarised in table 1 . The age of control subjects was $20-70$ years, with similar numbers in each decade. There was a significant difference in the regression correlation, either slope or intercept, between males and females for the sensory tests, and so the sexes were analysed separately. There was no significant difference between males and females for the electrophysiological or autonomic studies. The slope of the regression with age was not statistically significant for sural nerve conduction velocity nor in females for cooling or warming threshold or the size of the flare. All other parameters deteriorated significantly with increasing age.

The size of the sympathetic reflex vasoconstriction response was highly variable in control subjects, as has been found previously. ${ }^{19}$ Vasomotor fibres were only considered to be abnormal when the response to both stimuli was absent.

Sweating was absent on the soles of the feet of $20 \%$ of control subjects. This limited the value of the test in assessing abnormality in an individual subject, but comparisons of the incidence of absent sweating could be made between different clinical groups of diabetic subjects.

\section{Diabetic subjects}

The incidence of abnormalities in the different groups is shown in table 2 .

\section{Group I}

Not surprisingly, the lowest incidence of abnormality for all functions was in this group of long standing diabetics without clinically 
Table 1 Results for control subjects. In the calculation of regression correlation with age, log values have been used for all parameters except those marked *

\begin{tabular}{|c|c|c|c|c|c|c|c|c|c|}
\hline & \multirow[b]{2}{*}{$n$} & \multirow[b]{2}{*}{ Mean } & \multirow[b]{2}{*}{$S D$} & \multicolumn{6}{|c|}{ Regression correlation with age } \\
\hline & & & & $a$ & $b$ & $S D$ & $t$ & $r$ & $p$ \\
\hline $\begin{array}{l}\text { SVEL } \\
\text { SAMP } \\
\text { MAMP } \\
\text { VIB (M) } \\
\quad(\mathbf{F}) \\
\operatorname{COOL~}(\mathbf{M}) \\
\quad(\mathbf{F}) \\
\text { WARM (M) } \\
\quad(\mathbf{F}) \\
\text { FL (M) } \\
\quad(\mathbf{F}) \\
\text { IND (M) } \\
\quad(\mathbf{F}) \\
\text { BTDIF }\end{array}$ & $\begin{array}{l}34 \\
52 \\
34 \\
65 \\
65 \\
67 \\
72 \\
65 \\
72 \\
43 \\
37 \\
42 \\
37 \\
68\end{array}$ & $\begin{array}{r}45 \cdot 9 \\
15 \cdot 2 \\
5 \cdot 7 \\
8 \cdot 3 \\
8.9 \\
0 \cdot 3 \\
0 \cdot 2 \\
1.0 \\
0 \cdot 4 \\
11 \cdot 3 \\
11 \cdot 7 \\
0 \cdot 7 \\
0 \cdot 8 \\
25 \cdot 2\end{array}$ & $\begin{array}{r}12.65 \\
1.60 \\
1.59 \\
1.67 \\
1.33 \\
1.95 \\
1.80 \\
2.22 \\
2.08 \\
3.61 \\
3.18 \\
0.28 \\
0.28 \\
1.60\end{array}$ & $\begin{array}{r}\star 43.62 \\
3.22 \\
2.23 \\
1.36 \\
1.82 \\
-1.56 \\
-1.85 \\
-0.64 \\
-1.19 \\
3.39 \\
2.64 \\
\star 1.25 \\
\star 1.18 \\
4.22\end{array}$ & $\begin{array}{r}0.060 \\
-0.014 \\
-0.013 \\
0.025 \\
0.010 \\
0.012 \\
0.009 \\
0.017 \\
0.010 \\
-0.021 \\
-0.005 \\
-0.012 \\
-0.009 \\
-0.022\end{array}$ & $\begin{array}{r}12 \cdot 83 \\
0.44 \\
0 \cdot 44 \\
0 \cdot 27 \\
0 \cdot 25 \\
0 \cdot 67 \\
0.58 \\
0.77 \\
0.72 \\
0 \cdot 25 \\
0 \cdot 25 \\
0 \cdot 25 \\
0.27 \\
0.36\end{array}$ & $\begin{array}{r}0.35 \\
-2 \cdot 64 \\
-2 \cdot 20 \\
13.05 \\
4.68 \\
2.01 \\
1.88 \\
2.50 \\
1.84 \\
-6.25 \\
-1 \cdot 19 \\
-3.56 \\
-2 \cdot 25 \\
-7.00\end{array}$ & $\begin{array}{r}0.06 \\
-0.35 \\
-0.36 \\
0.85 \\
0.51 \\
0.24 \\
0.22 \\
0.30 \\
0.22 \\
-0.70 \\
-0.20 \\
-0.49 \\
-0.36 \\
-0.65\end{array}$ & $\begin{array}{l}>0.05 \\
<0.02 \\
<0.05 \\
<0.001 \\
<0.001 \\
<0.05 \\
>0.05 \\
<0.02 \\
>0.05 \\
<0.001 \\
>0.05 \\
<0.001 \\
<0.05 \\
<0.001\end{array}$ \\
\hline
\end{tabular}

SVEL = sural nerve conduction velocity $(\mathrm{m} / \mathrm{s}) ; \mathrm{SAMP}=$ sural nerve action potential amplitude $(\mathrm{uV}) ; \mathrm{MAMP}=$ muscle action potential amplitude $(\mathrm{mV}) ; \mathrm{VIB}=$ vibration perception threshold (biothesiometer units); $\mathrm{COOL}=$ cooling perception threshold potential amplitude $(\mathrm{mV})$; $\mathrm{VIB}=$ vibration perception threshold (biothesiometer units); $\mathrm{COOL}=$ cooling perception threshold
$\left({ }^{\circ} \mathrm{C}\right) ; \mathrm{WARM}=$ warming perception threshold $\left({ }^{\circ} \mathrm{C}\right) ; \mathrm{FL}=$ flare response (laser Doppler flux in $\left.\mathrm{mV}\right) ; \mathrm{IND}=$ vasodilatation index; $\left({ }^{\circ} \mathrm{C}\right) ; \mathrm{WARM}=$ warming perception
$\mathrm{BTD}$ IF $=\mathrm{RR}$ interval variability.

significant neuropathy. Warm perception (C fibres) was most frequently abnormal (in $45 \%$ ). The proportion of abnormalities for the two tests of Ab sensory function (vibration perception threshold and sural nerve action potential amplitude) was the same $(36 \%)$. Cooling perception threshold, sympathetic vasomotor function and parasympathetic heart rate variability were normal in all and the incidence of abnormal sweating was no higher than in control subjects.

There were only three subjects among the 11 tested in this group in whom no abnormalities were detected. In three others, abnormalities were confined to small fibres concerned with thermal perception (warming only in two), and in the remaining five, function of both large myelinated and small diameter fibres was disturbed. There were no subjects in whom abnormality was limited to large myelinated nerve fibre function.

\section{Group II}

Functional abnormalities were more severe in the group of subjects with mild clinical neuropathy. The highest incidence of abnormality was in large diameter (Ab) sensory fibres; warm perception (C fibres) were abnormal in approximately $60 \%$. Ad cooling fibres were abnormal in one third of this group and cardiac parasympathetic functions in a quarter.

Considerable evidence was placed on clinical abnormality of vibration perception threshold in selection of this group of patients for inclusion in a drug trial. This would account for finding some abnormality of $\mathrm{Ab}$ nerve function in all of them. Tests of Ad and C fibre functions were within normal limits in 11 of the 27.
All the patients with abnormal cooling perception also had abnormal warm perception and all those with abnormal cardiac autonomic function had abnormal thresholds for both cooling and warming.

\section{Group III}

The highest incidence of abnormality of all functions was seen in the group with foot complications. Sensory and motor nerve functions were abnormal in $78-96 \%$ of subjects. The incidence of abnormalities in peripheral and cardiac autonomic function was lower (33-53\%).

The findings in individual subjects in this group are summarised in table 3 . These demonstrate the variation in the pattern of neurological abnormalities in individual patients. In some there was greater involvement of small fibres, whereas in others large fibres were more affected.

Among the different groups of tests, there was only one patient (with a plantar ulcer) in whom Ab fibre function was entirely normal. Perception of warming was absent in all except two, in one of whom the threshold was abnormal.

In patients with neuroarthropathy, all motor and sensory functions were abnormal except in one subject, a young girl aged 20 . Her abnormalities were limited to sensory $C$ fibres and reduction of sural nerve action potential. She had developed a painless foot deformity three years previously over the course of three months following a bicycle accident.

There was an interesting difference in the sweating abnormalities between patients with plantar ulcers and arthropathy. Sweating was absent in seven of eight patients with an ulcer,

Table 2 Percentage of patients with abnormalities of the various nerve functions

\begin{tabular}{|c|c|c|c|c|c|c|c|c|c|c|c|}
\hline Group & $n$ & $S V E L$ & $S A M P$ & $M A M P$ & $V I B$ & $C O O L$ & $W A R M$ & $C N O C$ & $S W E A T^{\star}$ & VASOM & $B T D I F$ \\
\hline $\begin{array}{l}\text { I } \\
\text { II } \\
\text { III }\end{array}$ & $\begin{array}{l}11 \\
27 \\
23\end{array}$ & $\begin{array}{r}0 \\
33 \\
70\end{array}$ & $\begin{array}{l}36 \\
81 \\
95\end{array}$ & $\begin{array}{l}18 \\
44 \\
78\end{array}$ & $\begin{array}{l}36 \\
81 \\
87\end{array}$ & $\begin{array}{r}0 \\
33 \\
78\end{array}$ & $\begin{array}{l}45 \\
59 \\
96\end{array}$ & $\begin{array}{l}27 \\
83\end{array}$ & $\begin{array}{l}20 \\
52\end{array}$ & $\begin{array}{r}0 \\
33\end{array}$ & $\begin{array}{r}0 \\
26 \\
53\end{array}$ \\
\hline
\end{tabular}

* Sweating was absent on the soles of $20 \%$ of control subjects.

Abbreviations as in table 1. C NOC $=$ flare and/or vasodilatation index. 
Table 3 Results in individual subjects in Group III patients with foot complications

\begin{tabular}{|c|c|c|c|c|c|c|c|c|c|c|}
\hline \multirow[b]{2}{*}{ Age } & \multicolumn{4}{|l|}{$A b$} & \multirow{2}{*}{$\frac{A d}{C O O L}$} & \multicolumn{2}{|l|}{$C$} & \multicolumn{3}{|l|}{ Autonomic } \\
\hline & $S V E L$ & $S A M P$ & $M A M P$ & $V I B$ & & WARM & CNOC & SWEAT & VASOM & BTDIF \\
\hline $\begin{array}{l}\text { Group III a (skin lesions } \\
27 \\
32 \\
49 \\
53 \\
55\end{array}$ & $\begin{array}{l}\text { s) } \\
\mathrm{x} \\
\mathrm{O} \\
\mathrm{x} \\
\mathrm{Oo} \\
\mathrm{OoO}\end{array}$ & $\begin{array}{l}\text { O } \\
\text { oo } \\
\text { o } \\
\text { Oo } \\
\text { oo }\end{array}$ & $\begin{array}{l}\mathrm{O} \\
\mathrm{O} \\
\mathrm{x} \\
\mathrm{OO} \\
\mathrm{O}\end{array}$ & $\begin{array}{l}\text { o } \\
\text { O } \\
\text { o } \\
\text { oo } \\
\text { oo }\end{array}$ & $\begin{array}{l}\text { OO } \\
\text { O } \\
\text { Xo } \\
\text { oo } \\
\text { oo }\end{array}$ & $\begin{array}{l}\text { OO } \\
\text { oo } \\
\mathrm{x} \\
\text { Oo } \\
\text { Oo }\end{array}$ & $\begin{array}{l}\mathrm{O} \\
\mathrm{OO} \\
\mathrm{OO} \\
\mathrm{X} \\
\mathrm{x}\end{array}$ & $\begin{array}{l}\mathbf{x} \\
\mathbf{x} \\
\mathbf{x} \\
\text { Oo } \\
\mathbf{x}\end{array}$ & $\begin{array}{l}\mathrm{OO} \\
\mathrm{x} \\
\mathrm{X} \\
\mathrm{OO} \\
\mathrm{X}\end{array}$ & $\begin{array}{l}\mathbf{O} \\
\mathbf{O} \\
\mathbf{X} \\
\mathbf{O} \\
\mathbf{X}\end{array}$ \\
\hline $\begin{array}{l}\text { Group III b (plantar ulce } \\
43 \\
45 \\
47 \\
50 \\
51 \\
54 \\
58 \\
62 \\
62 \\
64\end{array}$ & $\begin{array}{l}\text { ers) } \\
\text { OO } \\
\text { OO } \\
\mathrm{X} \\
\mathrm{OO} \\
\mathrm{X} \\
\mathrm{X} \\
\mathrm{OO} \\
\mathrm{OO} \\
\mathrm{OO} \\
\mathrm{OO}\end{array}$ & $\begin{array}{l}\text { OO } \\
\text { OO } \\
\text { X } \\
\text { OO } \\
\text { O } \\
\text { O } \\
\text { OO } \\
\text { OO } \\
\text { OO } \\
\text { OO }\end{array}$ & $\begin{array}{l}\text { OO } \\
\text { OO } \\
\mathrm{x} \\
\mathrm{OO} \\
\mathrm{O} \\
\mathrm{O} \\
\mathrm{X} \\
\mathrm{O} \\
\mathrm{X} \\
\mathrm{O} \\
\mathrm{O}\end{array}$ & $\begin{array}{l}\text { OO } \\
\text { OO } \\
\text { X } \\
\text { O } \\
\text { O } \\
\text { O } \\
\text { X } \\
\text { Oo } \\
\text { OO } \\
\text { OO }\end{array}$ & $\begin{array}{l}\text { OO } \\
\mathrm{X} \\
\mathrm{OO} \\
\mathrm{OO} \\
\mathrm{OO} \\
\mathrm{O} \\
\mathrm{X} \\
\mathrm{OO} \\
\mathrm{OO} \\
\mathrm{X}\end{array}$ & $\begin{array}{l}\text { OO } \\
\text { OO } \\
\text { OO } \\
\text { OO } \\
\text { OO } \\
\text { OO } \\
\text { OO } \\
\text { OO } \\
\text { OO } \\
\text { OO }\end{array}$ & $\begin{array}{l}\text { OO } \\
\mathrm{O} \\
\mathrm{O} \\
\mathrm{O} \\
\mathrm{X} \\
\mathrm{O} \\
\mathrm{O} \\
\mathrm{OO} \\
\mathrm{X} \\
\mathrm{O}\end{array}$ & $\begin{array}{l}\text { OO } \\
\text { OO } \\
\text { OO } \\
\text { OO } \\
\text { OO } \\
\\
\text { X } \\
\text { OO } \\
\text { OO }\end{array}$ & $\begin{array}{l}\mathrm{OO} \\
\mathbf{X} \\
\mathbf{X} \\
\mathbf{X} \\
\mathbf{x} \\
\\
\mathbf{x} \\
\mathbf{x} \\
\mathrm{OO}\end{array}$ & $\begin{array}{l}\mathbf{0} \\
\mathbf{0} \\
\mathbf{0} \\
\mathbf{x} \\
\\
\mathbf{x} \\
\mathbf{x} \\
\mathbf{0}\end{array}$ \\
\hline $\begin{array}{l}\text { Group III c (neuroarthro } \\
20 \\
45 \\
48 \\
53 \\
53 \\
60 \\
66 \\
67\end{array}$ & $\begin{array}{l}\text { opathy) } \\
\text { X } \\
\text { OO } \\
\text { OO } \\
\text { OO } \\
\text { OO } \\
\text { OO } \\
\text { OO } \\
\text { X }\end{array}$ & $\begin{array}{l}\text { O } \\
\text { OO } \\
\text { OO } \\
\text { OO } \\
\text { OO } \\
\text { OO } \\
\text { OO } \\
\text { O }\end{array}$ & $\begin{array}{l}\mathrm{X} \\
\text { Oo } \\
\text { oO } \\
\text { oO } \\
\text { oO } \\
\text { OO } \\
\text { OO } \\
\text { OO }\end{array}$ & $\begin{array}{l}\text { X } \\
\text { O } \\
\text { O } \\
\text { oo } \\
\text { Oo } \\
\text { o } \\
\text { o } \\
\text { oo }\end{array}$ & $\begin{array}{l}\mathrm{X} \\
\text { OO } \\
\text { OO } \\
\text { OO } \\
\text { OO } \\
\text { OO } \\
\text { OO } \\
\text { OO }\end{array}$ & $\begin{array}{l}\text { O } \\
\text { OO } \\
\text { OO } \\
\text { OO } \\
\text { OO } \\
\text { OO } \\
\text { OO } \\
\text { OO }\end{array}$ & $\begin{array}{l}\text { oo } \\
\text { OO } \\
\text { o } \\
\text { O } \\
\text { oo } \\
\text { o } \\
\text { oo } \\
\text { Oo }\end{array}$ & $\begin{array}{l}\mathrm{X} \\
\mathrm{OO} \\
\mathrm{x} \\
\mathrm{OO} \\
\mathrm{OO} \\
\mathrm{X} \\
\mathrm{X} \\
\mathrm{X}\end{array}$ & $\begin{array}{l}\mathrm{X} \\
\mathrm{Oo} \\
\mathrm{X} \\
\mathrm{x} \\
\mathrm{OO} \\
\mathrm{OO} \\
\mathrm{x} \\
\mathrm{x}\end{array}$ & $\begin{array}{l}\mathbf{X} \\
\mathbf{0} \\
\mathbf{O} \\
\mathbf{X} \\
\mathbf{X} \\
\mathbf{X} \\
\mathbf{0}\end{array}$ \\
\hline
\end{tabular}

$\mathrm{X}=$ normal; $\mathrm{O}=\mathrm{abnormal} ; \mathrm{OO}=\mathrm{absent}$. Abbreviations as in tables 1 and 2.

but only three of eight with neuroarthropathy. In four of the arthropathy patients the stimulated sweat count was high in the control range.

Vibration and warming perception thresholds To demonstrate the relative value of these two tests in detecting minor degrees of neuropathy and in detecting deterioration or improvement in neuropathy, the values for individual subjects in the three groups are shown in relation to control ranges in the figure. A high proportion of subjects had abnormal results for both tests and the incidence of abnormalities for the two tests was not dissimilar in the different groups. This suggests that each of these tests is suitable for detection of neuropathy. Sural nerve action potential amplitude was a further suitable measure, since it also was abnormal in a similar number of subjects (table 2 ).

In many of the subjects with an abnormality of warm perception, the sensation was completely absent and only a few subjects in whom a threshold was measurable. This is partly related to the wide range of values found in control subjects, particularly at older ages. The situation for vibration perception threshold was different. Vibration sensation was absent in only ten, all of whom were in the group most severely affected clinically. Thus there were many in whom a value could be given to the abnormal threshold and hence scope for the detection of change. This makes vibration perception more useful than warming perception for following progress.

\section{Discussion}

In the past five years there has been a great increase in the commercial availability of different machines for quantitative sensory testing. These have been used both by neurophysiologists constrained by the limited range of fibres examined by nerve conduction studies and diabetologists in search of simple methods of assessing peripheral nerve function. Many recent reports of the results of sensory testing
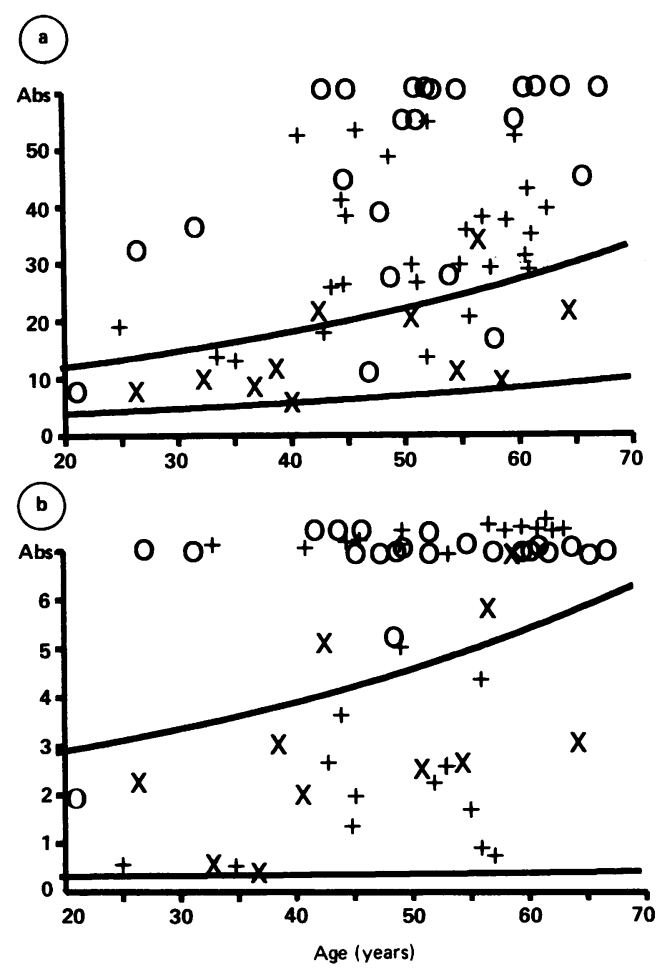

Figure Figure showing a) vibration and b) warming perception threshold for individual subjects in the different groups. $X-$ Group I; +-Group II; OGroup III. $y$ axis is in biothesiometer units in a) and in ${ }^{\circ} \mathrm{C}$ in $\left.\mathrm{b}\right)$. The lines indicate $95 \%$ confidence limits for control subjects, calculated from values for both males and females. Therefore, the proportions of abnormalities does not correspond exactly to those shown in table 2 , where the sex was taken into account in calculating control limits. 
in patients with diabetic peripheral neuropathy show considerable variance: Dyck's group found the threshold for cooling to be less frequently abnormal than large fibre function ${ }^{7}$ whereas Zeigler et al ${ }^{10}$ found it to be the most abnormal. Others using the Marstock thermal tester have found thermal thresholds to be more abnormal than vibration sensation. ${ }^{45}$ When electrophysiology has also been performed a high incidence of abnormality has been detected in sensory nerve action potentials. Levy et $a l^{6}$ found the medial plantar nerve action potential (recorded from a very distal nerve in the foot) to be more commonly abnormal than thermal sensitivity or vibration perception. Guy et al ${ }^{21}$ found sensory nerve action potentials in the hand to be more abnormal than vibration or thermal perception at the same site.

When interpreting the significance of the differing incidence of abnormality in the various tests, it is important to remember that this depends not only on the pathology of the different nerve fibres but also on the sensitivity of the tests. The capacity to detect abnormality is influenced both by the nature and design of the tests as well as the range of biological variability in control subjects. The clinical group of patients studied and site of the body tested are also important. These factors contribute to the lack of consistency as to which group of nerve fibres are most frequently abnormal in the studies described above.

Because of the lack of comparability of the different tests, our results cannot be taken as an indication of the severity of damage to different types of nerve fibre. They do, however, have practical implications in deciding which tests are the most suitable for detecting minor abnormalities and also those which are likely to be the most useful in assessing deterioration or improvement.

Threshold for perception of warming was highly abnormal, even in the least affected group, and is therefore a useful measure for detection of both minor and severe abnormalities. To perceive warming on the sole of the foot, it is necessary to use a large thermode in control subjects. Thus it is evident that summation of impulses in a number of fibres is necessary for perception. Patchy loss of some fibres will result in elevated threshold. This probably partly explains the sensitivity of this measurement. However, warm perception is a poor parameter for following progress, because it was absent at the highest stimulus level available in 14 of 27 subjects with only mild neuropathy. In the absence of a detectable threshold, minor degrees of improvement are unlikely to be detectable.

Although criticised because vibrations are not at right angles to the skin and because applied pressure is not controlled, in practical terms vibration perception threshold measured with a biothesiometer has proved highly reproducible. ${ }^{15}$ Its sensitivity has been shown in two studies ${ }^{14} 15$ which both found the same deterioration with age, further evidence of its reproducibility. A further study of the reproducibility of the test in control subjects has shown its adequacy for clinical use. ${ }^{16}$ As a screening tool for large numbers of subjects it has advantages of easy portability and speed. It can record a wide range of abnormal results since a wide range of stimulus intensities is available above the control threshold. A threshold was measurable in all patients in Groups I and II, and 13 of 23 in Group III, all of whom had severe neuropathy clinically. It has thus proved a good tool for detecting abnormality and a good candidate for following progress. However, it must be stressed that these comments only apply to data obtained with instruments which have been adjusted to a standard calibration.

Abnormalities of sural nerve action potential amplitude correlated well with abnormalities of vibration perception. Muscle action potentials were less frequently abnormal. However, in following the progress of the condition electrophysiological measures are less satisfactory. During regeneration, recovery of many electrophysiological parameters lags behind clinical recovery, depending on maturation of nerve fibres in addition to restoration of function.

Nociceptive $\mathrm{C}$ fibre function, assessed by measurement of the flare, was considerably abnormal in those with foot lesions, particularly those with neuroarthropathy. This highlights the importance of loss of both pain sensation and the neurogenic inflammatory response to injury in the aetiology of these lesions. ${ }^{22}$

Peripheral autonomic function tests were only considered to be abnormal when the responses were absent. This was because of a high biological variability of the responses in control subjects. Thus minor degrees of reduced function would not be recognised and the incidence of abnormality was low. This study confirms a previous observation on differential autonomic involvement in the various types of diabetic foot lesion. ${ }^{23}$ Sweating was absent in a high proportion of those with neuropathic plantar ulcers, but present in a high proportion of those with neuroarthropathy. Vasomotor reflexes were also present in a high proportion of the latter, necessitating reassessment of the possible role of vasomotor denervation in the aetiology. ${ }^{24}$

The low incidence of abnormality of cardiac autonomic function found in this study is at variance with a number of other studies in which autonomic function has been found to be abnormal in a high proportion of subjects and at an early stage of neuropathy. ${ }^{25}$ The most likely explanation is that only one autonomic cardiac function test was carried out, whereas it has been recommended that five should be used. ${ }^{25}$ Practical time constraints prevented this in our study.

These results confirm that, in distinction to many types of peripheral neuropathy which predominantly involve large diameter nerve fibres, small myelinated and unmyelinated nerves are frequently involved in diabetic neuropathy. There were a few patients in the least affected group clinically whose abnormalities were confined to small diameter nerve fibres, but none with large fibre dysfunction 
alone. However, this at least partly reflects the relative sensitivity of the tests rather than the number of abnormal nerve fibres in the different groups. Pure or predominantly small fibre disease of the type described by Said et al ${ }^{2}$ is rare and was not seen in this present study. When individual neuropathic profiles were considered it was obvious that there was considerable variability as to which type of fibre was most affected. It is possible that this heterogeneity is the result of multiple aetiological mechanisms in the production of neuropathy and if this is so, then any attempt to define a single pattern of abnormality in diabetic neuropathy is doomed to failure.

We thank Dr Anthony Kurtz for encouraging us to examine his patients, Mr Ken Robertson of The London Foot Hospital for his help in selecting and classifying the patients with foot lesions, The Sir Jules Thorn Charitable Trust for generous support The Sir Jules Thorn Charitable Trust for generous support while developing the tests, ICI Pharmaceuticals for support
while we collected the data from Group II patients, $\mathrm{Mr}$ Tarlok while we collected the data from Group II patients, Mr Tarlok
Gajree for invaluable technical help with the apparatus, and Mrs Gajree for invaluable technical help with the apparatus, and Mrs
Fay Kay and Mrs Olwyn Wade-Jones for collecting much of the Fay Kay and Mrs Olwyn
vibration perception data.

1 Brown MJ, Martin JR, Asbury AK. Painful diabetic neuropathy - a morphometric study. Arch Neurol 1976 30:164-71

2 Said G, Slama G, Selva J. Progressive centripetal degeneration of axons in small fibre diabetic polyneuropathy. A clinical and pathological study. Brain 1983;106:791-807.

3 Dyck PJ, Karnes J, O'Brien PC, Zimmerman IR. Detection threshold of cutaneous sensation in humans. In: Dyck PJ, Thomas PK, Lambert EH, Bunge R, eds. Peripheral Neuropathy 2nd ed. Philadelphia: Saunders, 1984: 1103-38.

4 Guy RJC, Clare CA, Malcolm PN, Watkins PJ. Evaluation of thermal and vibration sensation in diabetic neuropathy. Diabetologia 1985;28:131-7.

5 Bertelsmann FW, Heimans JJ, Weber EJM, van der Veen EA, Schouten JA. Thermal discrimination thresholds in normal subjects and in patients with diabetic neuropathy. J Neurol Neurosurg Psychiatry 1985;48:686-90.

6 Levy DM, Abraham RR, Abraham RM. Small and large fibre involvement in early diabetic neuropathy: a study with the medial plantar response and sensory thresholds. Diabetes Care 1987;10:441-7.

7 Dyck PJ, Bushek W, Spring EM, Karnes JL, Litchy WJ, O'Brien PC, Service FJ. Vibratory and cooling detection thresholds compared with other tests in dignosing and staging diabetic neuropathy. Diabetes Care 1987;10: $432-40$

8 Hilz MJ, Claus D, Neundorfer B. Early diagnosis of diabetic small fiber neuropathy by disturbed cold perception. $J$ Diab Complications 1988;2:38-43.

9 Sosenko JM, Kato M, Soto RA, Gadia MT, Ayyar DR. Specific assessments of warm and cool sensitivities in adult diabetic patients. Diabetes Care 1988;11:481-3.

10 Zeigler D, Mayer P, Gries FA. Evalution of thermal, pain, and vibration sensation threshold in newly diagnosed Type I diabetic patients. J Neurol Neurosurg Psychiatry 1988;51:1420-4.

11 Ali Z, Carroll M, Robertson KP, Fowler CJ. The extent of small fibre sensory neuropathy in diabetics with plantar foot ulceration. J Neurol Neurosurg Psychiatry 1989; 52:94-8.

12 Navarro X, Kennedy WR, Fries TJ. Small nerve fiber dysfunction in diabetic neuropathy. Muscle Nerve 1989; 12:498-507.

13 Report and Recommendations of the San Antonio Conference on Diabetic Neuropathy. Diabetes Care 1988; 11:592-7.

14 Bloom S, Till S, Sonksen P, Smith S. Use of a biothesiometer to measure individual vibration thresholds and their variation in 519 non-diabetic subjects. Brit Med $J$ 1984;288: 1793-5.

15 Le Quesne PM, Fowler CJ. Quantitative evaluation of toxic neuropathies in man. In: Ellingson RJ, Murray NMF,
Halliday AM, eds. The London Symposium. EEG J Suppl 1987;39:347-54.

16 Wardleworth A, Armstrong FM, Bradbury JE, Perkins CM. An assessment of the effect of age on vibration perception threshold in normal males and females. Diab Med 1987; 4(Suppl 6):591A.

17 Fowler CJ, Carroll MB, Burns D, Howe N. A portable system for measuring cutaneous thresholds for warming and cooling. J Neurol Neurosurg Psychiatry 1987; 50:1211-5.

18 Parkhouse N, Le Quesne PM. Quantitative objective assessment of peripheral nociceptive C fibre function. $J$ Neurol Neurosurg Psychiatry 1988;51:28-34.

19 Low PA, Neumann C, Duck PJ, Fealey RD, Tuck RR. Evaluation of skin vasomotor reflexes by using laser Doppler velocimetry. Mayo Clin Proc 1983;58:583-92.

20 Kennedy WR, Sakuta M, Sutherland D, Goetz FC. Quantitation of the sweating deficiency in diabetes mellitus. Ann Neurol 1984;15:482-8.

21 Guy RJC, Gilbey SG, Sheehy M, Asselman P, Watkins PJ. Diabetic neuropathy in the upper limb and the effect of Diabetic neuropathy in the upper limb and the effect of
twelve months sorbinil treatment. Diabetologia 1988; twelve mo

22 Parkhouse N, Le Quesne PM. Impaired neurogenic vascular response in patients with diabetes and neuropathic foot lesions. New Engl J Med 1988;318:1306-9.

23 Ahmed ME, Le Quesne PM. Quantitative sweat test in diabetics with neuropathic foot lesions. J Neurol Neurosurg Psychiatry 1986;49:1059-62.

24 Edmonds ME, Roberts VC, Watkins PJ. Blood flow in the diabetic neuropathic foot. Diabetologia 1982;22:9-15.

25 Ewing DJ, Clarke BF. Diabetic autonomic neuropathy: Present insights and future prospects. Diabetes Care 1986;9:648-65. 